\title{
Correction to: Differences in Diurnal Variation of Immune Responses in Microglia and Macrophages: Review and Perspectives
}

\author{
Ricardo J. Martínez-Tapia ${ }^{1,3}$ (C) Anahí Chavarría ${ }^{2}$ [ $\cdot$ Luz Navarro $^{1}[$
}

Published online: 10 October 2019

(c) Springer Science+Business Media, LLC, part of Springer Nature 2019

\section{Correction to: Cellular and Molecular Neurobiology https://doi.org/10.1007/s10571-019-00736-x}

The original version of this article unfortunately contained an error in the author group.

The given name and family name was interchanged for the two co-authors. The author name should be Anahí Chavarría and Luz Navarro instead it was published incorrectly as Chavarría Anahí and Navarro Luz.

The original article has been corrected.

Publisher's Note Springer Nature remains neutral with regard to jurisdictional claims in published maps and institutional affiliations.

The original article can be found online at https://doi.org/10.1007/ s10571-019-00736-x.

Luz Navarro

lnavarro@unam.mx

1 Neuroendocrinology Laboratory, Department of Physiology, Facultad de Medicina, Universidad Nacional Autónoma de México, 04510 Mexico City, Coyacán, Mexico

2 Unidad de Investigación en Medicina Experimental, Facultad de Medicina, Universidad Nacional Autónoma de México, Mexico City, Mexico

3 Programa de Doctorado en Ciencias Biomédicas, División de Estudios de Posgrado, Universidad Nacional Autónoma de México, Mexico City, Mexico 